\title{
Threshold concept learning: emotions and liminal space transitions
}

\author{
Gemma Irving, April Wright and Paul Hibbert
}

\begin{tabular}{|l|l|}
\hline Date of deposit & $18 / 02 / 2019$ \\
\hline Document version & Author's accepted manuscript \\
\hline Access rights & $\begin{array}{l}\text { Copyright (c) 2019, the authors, published by SAGE. } \\
\text { This work is made available online in accordance with the } \\
\text { publisher's policies. This is the author created, accepted version } \\
\text { manuscript following peer review and may differ slightly from the } \\
\text { final published version. }\end{array}$ \\
\hline $\begin{array}{l}\text { Citation for } \\
\text { published version }\end{array}$ & $\begin{array}{l}\text { Irving, G., Wright, A., \& Hibbert, P. C. (2019). Threshold } \\
\text { concept learning: emotions and liminal space transitions. } \\
\text { Management Learning, Forthcoming. }\end{array}$ \\
\hline $\begin{array}{l}\text { Link to published } \\
\text { version }\end{array}$ & https://journals.sagepub.com/loi/mlqb \\
\hline
\end{tabular}

Full metadata for this item is available in St Andrews Research

Repository at: https://research-repository.st-andrews.ac.uk/

\section{St Andrews Research Repository}




\title{
THRESHOLD CONCEPT LEARNING: EMOTIONS AND LIMINAL SPACE TRANSITIONS
}

\begin{abstract}
This article explores how learners transition through the liminal space when they engage with and master threshold concepts. We investigate this question through a qualitative study of undergraduate students as they grapple with the threshold concept of Evidence-based Management as a disciplinary way of thinking and practising. Our findings elaborate threshold concept learning as a cumulative process of learner engagement with the troublesome, integrative-and-bounded, irreversible, and transformative elements of a threshold concept. Through this elaboration, we show how transitions through liminal spaces in threshold concept learning play out as an interrelated cognitive and affective process. We identify key transition points and mechanisms related to doubt, high-activation negative emotions, regret, and emotional resolution that trigger entry into, progression through or getting stuck within, and exit from a liminal space when a learner engages with and masters a threshold concept. Our research therefore contributes processual insight into liminality in threshold concept learning by opening up the transitions and emotions that play out for learners in the liminal space. We also contribute to wider debates about student engagement with disciplinary ways of thinking and practising in management.
\end{abstract}




\section{THRESHOLD CONCEPT LEARNING: EMOTIONS AND LIMINAL SPACE TRANSITIONS}

\section{INTRODUCTION}

Scholars have recently begun to explore threshold concepts and their implications for learning of, and about, management theory and practice (Hawkins \& Edwards, 2015; Wright \& Hibbert, 2015). Threshold concepts are defined as troublesome concepts that may initially seem alien or counterintuitive but which, once mastered, open up 'a new and previously inaccessible way of thinking about something ... a transformed way of understanding, or interpreting, or viewing something' (Meyer \& Land, 2003:1). Threshold concepts are both troublesome and transformative for novice learners because they link to ways of thinking and practising in academic disciplines and open up the distinctive worldviews of graduate professions (Meyer \& Land, 2005). In the field of management learning, some scholars have focused attention on threshold concepts and the modalities they create for teaching and learning in domains like leadership practice (Yip \& Raelin, 2012), introductory management (Wright \& Gilmore, 2012), and business ethics (Hibbert \& Cunliffe, 2015). Other scholars have elaborated threshold concepts through their situatedness within a liminal process in which learners progress through an in-between state of doubt and uncertainty to a new transformed understanding (Hawkins \& Edwards, 2015; Hay \& Samra-Fredericks, 2016).

We seek to connect these two lines of inquiry by exploring how learners come to understand threshold concepts through their experience of liminality. In order to grasp a threshold concept, learners enter a liminal space of 'being betwixt and between' when they realise that their previous understandings are inadequate but before they have fully developed a new understanding (Meyer \& Land, 2005; Turner, 1977). Management learning scholars have called for more research into how learners engage with threshold concepts as they move 
into, through and out of the liminal space in their learning journey (Hibbert \& Cunliffe, 2015; Yip \& Raelin, 2012). Although the literature hints at the role of emotions, especially doubt (Hawkins \& Edwards, 2015; Hay \& Samra-Fredericks, 2016) in facilitating a learner's passage, we lack deep and nuanced insight into how shifts in understanding unfold across the liminal space when a learner is exposed to a threshold concept.

We explore these issues through a qualitative study of undergraduate student learning. Our empirical study focuses on the threshold concept of evidence-based management, defined as the judicious use of best available evidence to inform decision-making (Rousseau, 2006). EBMgt is a disciplinary way of thinking and practising that is contested among management scholars (Morrell \& Learmonth, 2015). EBMgt fits the characteristics of a threshold concept because it is troublesome for students to grasp but transformative when they do (Meyer \& Land, 2003; Rousseau \& McCarthy, 2007). Prior research (Rousseau, 2006; Trank, 2014; Wright \& Gilmore, 2012), along with our own primary data collected for this study, indicate that novice business students find the idea of applying scientific evidence to management-type problems to be counter-intuitive and hence troublesome. Yet since 'evidence-based practice is a way of looking at the world' (Barends \& Briner, 2014: 481), crossing the liminal space and grasping EBMgt opens up a new and transformed way among multiple ways - of understanding management as an academic discipline and of thinking like an evidence-based manager.

The findings of our study make three contributions to the literature. First, while previous research has pointed to threshold concepts as a 'catalyst for learning (Yip \& Raelin, 2012:348), we offer new insight into the mechanisms that act as catalysts in the learning process. We elaborate threshold concept learning as a cumulative process of learner engagement with the troublesome, integrative-and-bounded, irreversible, and transformative elements of a threshold concept as a disciplinary way of thinking and practising. Second, we 
contribute to the literature on liminality in management learning by opening up how transitions through liminal spaces play out as an interrelated cognitive and affective process. Our process model elaborates the transition points and mechanisms related to doubt, highactivation negative emotions, regret, and emotional resolution that trigger entry into, progression through or getting stuck within, and exit from a liminal space when a learner engages with and masters a threshold concept. Third, we contribute to wider debates about disciplinary ways of thinking and practising in management by showing how educators can help undergraduate students engage critically with a threshold concept as one way - amongst multiple ways in the discipline's underlying game - of thinking and practising. An implication of our study is that when educators approach teaching and learning at the undergraduate level as nests of inter-related and bounded threshold concepts, learners' existing understandings can be refined and critiqued as they engage with more threshold concepts and accumulate experiences with navigating liminal spaces.

Our article is structured as follows. We begin by outlining the management learning literature on threshold concepts, liminality, and the potential role of emotions in the learner's transition through a liminal space. Next, we explain our research interest in exploring liminal space at the undergraduate level and set out our arguments for studying evidence-based management as a threshold concept. We then describe the method used to collect and analyse empirical material in our qualitative study, before reporting our findings. We conclude with a discussion of the contributions and implications of our process model of transitioning through liminal space in threshold concept learning.

\section{THRESHOLD CONCEPTS}

Threshold concepts are ideas that act as conceptual gateways to transformed understandings of the ways of thinking and practising within a discipline or field of study (Meyer \& Land, 2003; Meyer \& Land, 2006). Building on the seminal work of Meyer and 
Land (2003), threshold concepts are distinguished by five characteristics. First, threshold concepts are associated with troublesome knowledge, which is uncomfortable and counterintuitive for learners to engage with because it challenges their pre-existing understandings of a phenomenon (Perkins, 1999). Second, threshold concepts are integrative, pulling together and making connections between different phenomena and disciplinary knowledge that were previously hidden from the learner's view (Meyer \& Land, 2005). Third, threshold concepts have irreversible effects because they are unlikely to be forgotten once the flaws in simpler understandings have been exposed (Hibbert \& Cunliffe, 2015). Irreversibility does not exclude the learner modifying or refining their understanding of a particular threshold concept as they master other threshold concepts associated with disciplinary ways of thinking (Hawkins \& Edwards, 2015). Fourth, threshold concepts are bounded. Sharing borders with thresholds in other conceptual domains and other fields of disciplinary knowledge, every threshold concept has terminal frontiers that demarcate and delimit the scope of its application within a discipline's ways of thinking and practising (Davies \& Mangan, 2007). Fifth, threshold concepts are transformative because grasping the concept changes a learner's worldview of a discipline and how they see themselves within it (Meyer \& Land, 2005).

Threshold concept learning has enjoyed increasing attention over the past fifteen years. In disciplines outside management, scholars have explored how learners struggle with threshold concepts as varied as opportunity cost in economics, gravity in physics, complex numbers in mathematics, deconstruction in English literature, and depreciation in accounting (Davies \& Mangan, 2007; Irvine \& Carmichael, 2009; Lucas \& Mladenovic, 2007; Scheja \& Pettersson, 2009). While research into threshold concepts has been slower to take off in the field of management (Hibbert \& Cunliffe, 2015), recent studies suggest that threshold concepts play an important, albeit not yet well understood, role in management learning (Wright \& Hibbert, 2015). Studies have typically focused on research questions that 
investigate what threshold concepts exist in management courses at undergraduate, postgraduate, and MBA levels and what practices educators can use to support their mastery. These studies have identified a growing pool of threshold concepts including entrepreneurial failure (Bolinger \& Brown, 2015), leadership theories (Yip \& Raelin, 2012), reflexivity (Hibbert \& Cunliffe, 2015), and ethics, responsibility and sustainability (Duarte, 2013; Vidal, Smith, \& Spetic, 2015). Other scholars have exposed how the 'underlying game' (Perkins, 2006) of the management discipline creates a threshold conception that 'management is a practice informed by theory', a conception that undergraduate students in introductory management courses find troublesome and transformative (Wright \& Gilmore, 2012). Threshold conceptions "bind together aspects of a subject that may seem quite disparate to a novice" but are "fundamental to ways of thinking and practising in that discipline" (Land et al., 2005, p. 54). The material that is bound together in the threshold conception of management (management is a practice informed by theory) may include a variety of threshold concepts. Teaching practices that may promote management learning through particular threshold concepts include case studies, research-based assignments and simulations (Burch, Burch, Bradley, \& Heller, 2015; Nichols \& Wright, 2015; Romme \& Seggelen-Damen, 2015).

\section{LIMINALITY AND THRESHOLD CONCEPT LEARNING}

A nascent line of inquiry in management learning has begun to explore the experience of liminality inherent in how learners engage with threshold concepts (Hawkins \& Edwards, 2015; Hay \& Samra-Fredericks, 2016). Liminality is a concept from social anthropology that defines the temporal phase and social space in the middle of a ritual and involves a sense of being 'betwixt and between' (Turner, 1977; Van Gennep, 1960). People enter a liminal space after they have shed an old status or identity- for example as a girl- and before they adopt a new status or identity- for example as a woman (Van Gennep, 1960). In classic anthropology, 
liminal space is associated with the suspension of established norms, rules, and routines and thus with ambiguity (Turner, 1977). Management scholars have invoked the concept of liminality to better understand the lived experience of individuals in contexts that are changing, flexible, or at a threshold (Bamber, Allen-Collinson, \& McCormack, 2017; Borg \& Soderland, 2015). In doing so, management scholars have focused on permanent experiences of liminality at the expense of 'investigating the temporality of liminality... [including] the ritual order associated with it' (Söderlund \& Borg, 2017: 19). In translating the concept of liminality to threshold learning processes, management researchers have begun to explore the temporal experience of grappling with new and unfamiliar threshold concepts - which reflect the management discipline's different ways of thinking and practising - and its similarity with the experience of liminality during a ritual (Hawkins \& Edwards, 2015; Simpson, Sturges, \& Weight, 2009).

Learners master a threshold concept when they transition across a liminal space from a pre-liminal to a liminal to a post-liminal understanding (Perkins, 2006). As they grapple with counter-intuitive disciplinary knowledge, learners shift from common-sense understandings of management phenomena to a liminal state of troublesome in-between-ness and onward to a post-liminal state of transformed understanding in which they begin to think like a disciplinary scholar (Meyer \& Land, 2005; Scheja \& Pettersson, 2009). When learners undertake courses in management and leadership, for example, the post-liminal state is marked by coming to 'think like a management scholar' (Wright \& Gilmore, 2012) and to 'think like a leadership scholar' (Hawkins \& Edwards, 2015). Crossing the threshold to a new understanding requires a learner to realize the inadequacy of their previous understanding of management phenomena and wrestle with alternative ways of thinking and seeing (Meyer \& Land, 2005). The liminal space which exists 'betwixt and between' old and new understandings has the potential to facilitate integrative, bounded, irreversible, and 
transformative learning of a threshold concept - which nests within and also borders against other threshold concepts - by opening up a transitional space for learners to confront counterintuitive ideas grounded in management as a discipline (Hawkins \& Edwards, 2015).

Yet while recent work has illuminated the significance of liminality to learning of threshold concepts in management, scholarly insight into the triggers and mechanisms that support learners to transition across the liminal space is limited. A small body of research points to, but does not substantively elaborate, some of the mechanisms that may be involved in crossing the liminal space. Research into temporary project workers and MBA students suggests that increasing the scope and breadth of exposure to liminal experiences may support learning provided there is sufficient time for reflection (Borg \& Soderland, 2015; Simpson et al., 2009; Tempest \& Starkey, 2004). Critical refection and questioning helps undergraduate students in leadership courses to grasp the nested threshold concepts that cohere into thinking like a leadership scholar (Hawkins \& Edwards, 2015). Emotions, too, are a feature of the liminal space (Cousins, 2006). Disruption of existing understandings and identities - which is necessary for transformative learning of threshold concepts - can arouse doubt, anxiety, and confusion for learners (Hawkins \& Edwards, 2015; Hay \& SamraFredericks, 2016), while positive emotions may arise if learners feel excitement and anticipation at possibilities for new experiences (Beard, Clegg, \& Smith, 2007; Kempster, Turner, Heneberry, Stead, \& Elliott, 2015). Emotions are also aroused as students transition into new identities as undergraduate, MBA or DBA students (e.g. Gourlay, 2009; Hay \& Samra-Fredericks, 2016; Simpson et al., 2009) and these liminal experiences help learners think in new ways and develop new identities as managers upon graduation (Simpson et al., 2009). Finally, emotions may halt transitions across the liminal space if anxiety and doubt morphs into helplessness, anger, and panic (Gilmore \& Anderson, 2011, 2016), resulting in a learner getting 'stuck' at a threshold concept (Meyer \& Land, 2005). 
These previous studies have illuminated an important relationship between liminality and threshold concepts in management. We argue that advancing scholarly insight now requires deeper interrogation of the processes through which learners transition through the liminal space to new ways of thinking and practising rooted in management as an academic discipline. The literature hints at a potential role for emotions in facilitating or halting transitions in the learning journey. However, scholars and management educators know little about the dynamic mechanisms through which emotions shape liminality and threshold concept learning. Thus, we seek to contribute to the literature by investigating the following research question: How do learners transition through a liminal space when they engage with a threshold concept and what role do emotions play in this process?

\section{EXPLORING EVIDENCE-BASED MANAGEMENT AS A THRESHOLD CONCEPT}

Previous studies examining liminality in threshold concept learning have explored management learners in undergraduate (Hawkins \& Edwards, 2015; Wright \& Gilmore, 2012; Yip \& Raelin, 2012), MBA (Simpson et al., 2009) and DBA programmes (Hay \& Samra-Fredericks, 2016). We join the first group of scholars in focusing our attention on undergraduate learners. As noted by Hawkins and Edwards (2015:411), 'helping undergraduate students grasp threshold concepts can facilitate their diverse, personal encounters' with liminal spaces, supporting them to wrestle and come to terms with doubt as they experience different threshold concepts within management as an academic discipline. This view is echoed in the threshold concepts literature (Meyer \& Land, 2006). How an undergraduate student understands a discipline's ways of thinking and practising through exposure to threshold concepts as a novice learner shapes their progression in current and future courses and as a practising professional (Davies \& Mangan, 2007; Hibbert \& Cunliffe, 2015; Meyer \& Land, 2005). 
In addressing our research question through an empirical study of undergraduate students, we chose to investigate their engagement with the threshold concept of evidencebased management (EBMgt). Inspired by evidence-based practice in medicine (Barends \& Briner, 2014), EBMgt is an approach to decision-making informed by 'critical evaluation of the best available research evidence' combined with judicious use of other sources of information (Briner, Denyer, \& Rousseau, 2009: 19). EBMgt emerged as a response to concerns that, in practice, managers made decisions based on past behaviour, gut instincts, and faulty logic (Pfeffer \& Sutton, 2006; Rousseau, 2006; Rousseau \& McCarthy, 2007). Although EBMgt has gained popularity as 'a way of thinking' about management (Rynes, Rousseau, \& Barends, 2014), EBMgt is not without criticism. Critics question EBMgt's privileging of science and rationality over other forms of knowledge such as intuition and experience (Hornung, 2012; Morrell, 2012) and have criticised EBMgt's essentially positivist assumptions, managerialist values, and hegemonizing discourse (Learmonth, 2008; Morrell, 2008; Morrell, Learmonth, \& Heracleous, 2015; Tourish, 2013). Of great concern to some scholars is the concept's basis in narrow and select hierarchies of evidence (Learmonth, 2006; Morrell \& Learmonth, 2015; Reay, Berta, \& Kohn, 2009) and its devaluation of stories and narrative forms of knowledge (Morrell \& Learmonth, 2015). Others have challenged the trustworthiness of the management discipline's cumulative scientific knowledge (Kepes, Bennett, \& McDaniel, 2014). Concepts that attract or even drive vigorous debate are helpful for developing the critical and socially reflexive skills of students (Hibbert \& Cunliffe, 2015) and thus have educational value whether they are adopted, adapted or simply critiqued by students in their engagement with them. The ongoing debates about EBMgt also point to its troublesome character as one possible way - among multiple ways - of thinking and practising in the management discipline and open up its potential as a threshold concept. 


\section{Threshold Concept Characteristics of Evidence-based Management}

EBMgt has the troublesome characteristic of a threshold concept. When educators introduce EBMgt in their course curricula, many students will perceive the concept of applying scientific evidence in management decision-making as troublesome. This is especially likely to be true for undergraduate students in introductory management courses because - as research in the threshold concepts literature has uncovered - novice students in these courses struggle to grasp the discipline's 'underlying game' that 'management is a practice informed by theory' (Perkins, 2006; Wright \& Gilmore, 2012). Given that scholars dispute how EBMgt fits within the disciplinary game, we infer the concept of evidence-based practice may seem counter-intuitive to undergraduate students entering introductory management courses with common-sense understandings of how managers work in organizations.

In addition, the debates over EBMgt point to its transformative potential as a threshold concept. Advocates argue that 'evidence-based practice is a way of looking at the world' (Barends \& Briner, 2014:481) and when educators teach EBMgt, they are preparing students 'to be active consumers and users of research as professionals' after graduation (Trank, 2014:384). This argument suggests that when an undergraduate student in an introductory management course masters EBMgt, their common-sense understanding of management is transformed into a new understanding of how to think like a management scholar in an evidence-based way. Yet, as critics assert, EBMgt is but one possible way of thinking within the discipline's underlying game and that many other ways - and perhaps disciplinary games themselves - are legitimate in a pluralistic and inclusive management discipline (Morrell, 2008; Morrell \& Learmonth, 2015), suggesting that EBMgt has the integrative and bounded characteristic of a threshold concept. 
Finally, the writings about EBMgt hint at its potential irreversibility. Even critics of EBMgt acknowledge 'There is a lot to commend in a vision of practice informed by scholarship where managers exercise careful, reasoned judgment... [and] where they draw sensibly on research' (Morrell \& Learmonth, 2015:521). Having mastered EBMgt as one way of thinking about management, the novice student in an introductory management course might be expected to find such transformative thinking difficult to unlearn (Rousseau \& McCarthy, 2007; Wright, Irving, Hibbert \&Greenfield, 2018). Taken together, these characteristics suggest EBMgt may be a threshold concept in undergraduate student learning suitable for empirical study guided by our research question.

\section{METHOD}

The empirical data reported in this article are taken from a larger qualitative study of student experiences in an Introductory Management course, part of an AACSB-accredited undergraduate program at an Australian university, with enrolment around 1200 mostly firstyear students. The threshold concept of EBMgt was first introduced in a lecture, with students then required to read Rousseau and McCarthy's (2007) article about EBMgt before undertaking small-group discussions in class facilitated by instructors who opened up the concept of EBMgt and its critiques. Next, students participated in class in an online simulation, the 'Leadership and Team Simulation: Everest V2' released by Harvard Business Publishing, to provide a shared experiential context for subsequent application of EBMgt. The simulation storyline concerns a commercial expedition to climb Mount Everest. Hiking virtually to the summit over successive rounds of play, students are assigned specified roles on five-person teams and make decisions together within constraints related to information and resource availability, weather conditions, climbers' physical health, time, and risk of rescue or death. After participating in the Everest simulation, students then completed an assignment that required them to follow the four-step process for doing EBMgt as outlined by 
Rousseau and McCarthy (2007, p.88) by: identifying problems in their team's decisionmaking during the simulation; searching the scholarly management literature for research evidence pertinent to their identified problems; evaluating if and how the available research evidence could have better informed their decision-making and addressed the problems; and recommending improvements based on the evidence found. As part of the assignment task, students were explicitly asked to write a reflection on their understanding of and experience with applying EBMgt based on the Rousseau and McCarthy (2007) article. Students reported their EBMgt process and reflection in a 2000-word assignment.

After the final course grades were released, all students enrolled in the course were invited to participate in the study. In total, 223 students responded favourably and agreed to their course assignment being included in the study (a response rate of over 18\%). The sample comprises 74 males and 149 females. There is no significant difference between the mean assignment grades for the participant sample and the course population.

Data analysis was guided by our research question as well as guidelines for working with student reflection texts suggested by other authors (Dyer \& Hurd, 2016). We began by using the literature on threshold concepts as a sensitizing framework (Corbin \& Strauss, 2008). After becoming familiar with the empirical material by reading and re-reading the student assignments, we found that we could categorise different assignments according to if and how the student engaged with the troublesome, integrative, bounded, irreversible and transformative elements of EBMgt as a threshold concept. Our coding indicated these elements could be arrayed as the following transitions in a liminal space: The text in 31 assignments expressed a troublesome understanding of EBMgt. The text in 84 assignments had moved beyond troublesome to an integrative-and-bounded understanding of EBMgt. The text in 67 assignments had shifted from troublesome to integrative-and-bounded and onwards to an irreversible understanding of EBMgt. Our coding suggested that these 67 assignments, 
along with a further 35 assignments, had exited the liminal space by synthesising their new view of EBMgt into a transformative understanding. We were unable to categorise 6 student assignments that lacked sufficient content.

Having arrayed the different learner understandings of EBMgt as a threshold concept in the liminal space, we then undertook more systematic analysis of our research question by seeking to identify the mechanisms that facilitated the processes of transition from one understanding to the next. Guided by our research question, we were attentive to segments of text that expressed emotions in transitions in student understanding of EBMgt. Comparing iteratively within and across the text of assignments in each of our threshold categories (Strauss \& Corbin, 1990), we were struck by some common themes in how students reflected cognitively and affectively on their experiences at each transition. Our coding suggested that doubt activated entry into the liminal space and an understanding of EBMgt as troublesome; mechanisms of high-activation negative emotions and an other-oriented focus triggered a shift to an integrative-and-bounded understanding; mechanisms of regret and self-oriented focus triggered a shift to irreversibility; and mechanisms of emotional resolution and conceptual settlement triggered exit from the liminal space and a transformative understanding of EBMgt. We describe these mechanisms in detail in the findings that follow.

\section{FINDINGS}

Our findings explicate a process of how students navigate liminality in their engagement with EBMgt. Different elements of EBMgt as a threshold concept come into view in a progressive process as students enter, move through, and exit the liminal space. We illustrate the transitions in student understanding with examples of text from our empirical materials using identifier codes S1 to S44.

Transition T0: Entering the liminal space, EBMgt is Troublesome 
Initially, students found the concept of EBMgt - as a way of thinking and doing management based on using the 'best available scientific evidence' to inform decisionmaking - troublesome. This troublesomeness arose from a confrontation between EBMgt and the student's preconceptions of management as an applied discipline that is unlike the fields of knowledge and practice in science-based academic disciplines. As one student noted, 'I originally believed that EBMgt would only be applicable to practical fields, for example medicine and science' (S1). Since 'medicine has long established and ongoing professional research' and management does not, students expressed doubt about whether managers could 'have access to the masses of base data required for making evidence-based decisions' (S2). Applying principles derived from an epistemology of natural science to management as a social science seemed counter-intuitive, with students pointing out that 'management, unlike medicine and science, deals with human behaviour which is often erratic and unpredictable' (S3). The extract below captures the troublesomeness of EBMgt and student doubt about engaging with it:

Not all organisations operate the same. Not all the evidence can be applied to a minority of people, as most evidence is based around the mean of an experimental group. For example, even the best medicine can have its side effects on different people ... My biggest issue with EBMgt is applying results to individuals ... The industries I will be working in such as tourism, events and hospitality will not appropriately support EBMgt because it is more suited for medicine. (S4)

\section{Transition T1: Troublesome to Integrative-and-Bounded}

Our data indicates that doubtful students can move beyond their initial understanding of EBMgt as troublesome knowledge by transitioning through the liminal space. The first transition (T1) involved a student's experiences in the Everest simulation exposing the previously hidden interrelatedness of EBMgt to decision-making in some management situations. The extract below illustrates the opening up of a previously inaccessible conceptual gateway to EBMgt: 
Throughout the course of this assignment and topic, my beliefs towards EBMgt have changed. In the beginning my view was obscured and I did not see much point in learning it, probably much like other students. ... [EBMgt seemed more] central to effective practice in medicine, education, policing and psychology. As the information progressed and as students were able to apply EBMgt to a situation, my thoughts on EBMgt changed. Using EBMgt allowed me to uncover and use other points of views on decisions that I would usually not become aware of. (S5)

Students at the T1 transition had gained 'a better understanding of ... how management theory related to practice, as well as how scientific evidence underpins management decisions' (S6). The simulation experience was sufficiently persuasive for them to wrestle past their initial troublesome engagement with EBMgt to get a glimpse of how evidence-based decision processes ‘using behavioural science research' (S7) could potentially be integrated within an understanding of management theory. For the student, 'it became clear after completing the simulation that [EBMgt] ... can be related quite closely back to management theory' (S6). Students could see how they might 'apply EBMgt principles through diagnosing the underlying factors of my issue, researching evidence from well-regarded studies, and adapting knowledge to my particular circumstance' (S8). An integrative understanding of EBMgt opens up the student's view to 'logical relationships between the evidence and core theoretical concepts' (S9).

Our data suggests that, as the previously hidden inter-relatedness of evidence-based ways of thinking to management come into view, so too the contextual boundaries around EBMgt are made clearer. Students see not only 'the marriage between human behavioural sciences' (S10) and EBMgt, but also the terminal frontiers of that relationship. As a student noted, 'I can understand how the evidence-based approach is not always appropriate for every organization dealing with real world problems.' (S20). Contextual boundaries shape when and how EBMgt can be applied in organizations because 'no scientific evidence can account for all the circumstances surrounding a [management] decision' (S11) and 'theory does not translate perfectly into practice' in management situations where many variables are in play 
(S3). Finding and evaluating the 'right data' to diagnose problems and support management decisions is time-consuming, with no guarantee that available scientific data has any 'relation to the current issue' (S12). As students observed, EBMgt needs to generate 'a customised solution rather than a transposed standard-form solution' like those in medical interventions and treatments (S13) and 'not all organizations will be cured with one method' (S14). By acknowledging that ideas about evidence from medicine and science are not universally generalizable to management as a social science, a bounded understanding of EBMgt as a way of thinking reduces its troublesomeness as a threshold concept:

On reading the article prior to the assignment, my initial thoughts were that EBMgt would be difficult to put into practice and have uncertain results. During my own working life I have only seen a more traditional style of management. However, it was easy to see the benefits to the medical profession. After further research for the assignment, I can see how it would benefit some organisations. (S15)

The above extract illustrates how a transition from a troublesome understanding of EBMgt is achieved by viewing the threshold concept through a new lens which is both integrative and bounded. EBMgt is viewed as conceptually inter-related to management theory but contextually bounded in its relevance and applicability to some organizations - but not all. Below, another student describes how recognition of terminal frontiers and contextual boundaries around EBMgt aided their journey across the liminal space:

When researching for this assignment, I often found the current collection of management evidence was too broad, conceptual, or scarce to be applied to my specific issue and situation at hand. ... Whilst EBMgt certainly has value in management ... management is inherently unpredictable - whether it be the environment and because of human behaviour. As a result, management will call for different applications or approaches all the time. (S3)

Our data suggest that high-activation negative emotions may act as a mechanism in the $\mathrm{T} 1$ transition from troublesome to integrated-and-bounded understanding. The simulation provided students with 'a thought-provoking and emotional experience' (S16) and for some groups, 'each decision set elicited an emotional response from each team member' (S17). Experiencing uncertain decision situations 'caused stress and anxiety' (S18). Emotional stress 
was triggered when team members fell ill or weather equipment failed. Students described how 'the experience was daunting' (S19) and 'we had panicked' (S12). Feeling 'overwhelmed' (S20), 'worried' (S21) and 'upset' (S22), students reported that 'confusion set into the team as to what to do' (S23). As a student explains:

The group was placed under tremendous... uncertainty on what would be the most optimal decision route to take ... Emotions felt in the simulation experience can be used to identify dilemmas. (S24)

In response to such emotional stimulus, our data indicates students are shocked or 'surprised' (S25) into questioning their starting position that evidence-based approaches in science-based disciplines do not relate to decision situations involving managers and organizations. Potential inter-relationships among scientific evidence and management decision-making are exposed when the student senses that their emotional anxiety could have been eased if they had access to relevant sources of evidence to support decision-making. Students see that evidence-based principles derived from research studies into, for example, group processes and cognitive biases could have provided insights that reduced 'the resulting stress of making decisions' (S26). A student explained:

As a student when making the decisions for the simulation ... the only process considered was to get to the summit as fast as possible without a team member needing to be rescued. ... An experienced manager would have taken the time to critically analyse possible outcomes, worked out the underlying factors relating to the decision, and with EBMgt would have used evidence to find a solution. (S27)

The student's explanation is about some 'other' that might engage with EBMgt - the 'experienced manager' - and not himself. Our data indicates that an other-oriented focus is typical of students at the $\mathrm{T} 1$ transition. Supporting the experience of high-activation negative emotions as a mechanism of transition, an other-oriented focus allows a student to integrate EBMgt into their understanding of management. More specifically, they come to view EBMgt as theoretical knowledge which may apply to generalized others, rather than the particular self, within contextual boundaries: 'evidence found in authoritative journal articles 
gives us an idea of how to provide solutions to similar problems in the business world' (S28). Together, the two mechanisms of high-activation negative emotions and other-oriented focus trigger progression from a troublesome to an integrative-and-bounded understanding of EBMgt.

\section{Transition T2: Integrative-and-Bounded to Irreversible}

A second transition (T2) marks the shift from an integrative-and-bounded understanding of EBMgt to an irreversible understanding. Here the student's understanding that EBMgt can be useful for management practice, within appropriate contextual boundaries, becomes difficult for the student to unlearn or forget, as this extract illustrates:

This rash decision ... meant $\mathrm{M}$ needed rescuing. ... Through the post-simulation analysis, I learnt that our group could have done so much better by modifying our attitudes, practices and culture to more accurately replicate the scientifically tried and tested methods. ... Even though we did a lot of things wrong in the management of our team, it's sometimes in doing things incorrectly that you learn the most. (S29)

Our data suggests that regret is a key mechanism in the transition process to irreversible knowledge that is difficult to unlearn. When the student experienced 'feelings of regret ... [about] their decisions and ending with the negative consequences' (S26), this retrospective reflection on a regretted decision made it difficult to unlearn EBMgt as a threshold concept. Regret was elicited when 'an extremely serious issue ... [arose as] the culmination of a breakdown in decision-making' (S30) during the simulation, such as the rescue of team members and the failure to achieve team goals. One student noted, for example, that 'countless faults in the group's decision-making processes' meant they had 'regrettably administered' the supply of medications ineffectively and no team members reached the summit (S31). Other students regretted the 'managerial mistakes' (S32), 'flawed discussions' (S33), and 'incorrect decisions' (S34) they made during the simulation and lamented that 'this is a lose-lose ending' (S35). 
In reflecting on the cause of their regretted decision, some students - who had integrated EBMgt within an understanding of management theory at the T1 transition - began to make new connections between evidence and practical actions at the $\mathrm{T} 2$ transition. Reflection on a regretted decision brought into view the potential for evidence to inform decisions and reduce negative consequences in management-type situations. Many students blamed the regretted decision on intuitive and ad hoc decision-making during the simulation: 'I found intuition to be an ineffective form of decision making' (S36). Signalling their progression across the liminal space towards a new understanding of EBMgt as a threshold concept, these students came to see that regret might have been avoided if they had applied principles of EBMgt. Recalling 'decisions being made quite hastily' during the simulation based on gut instincts, a student contemplated, for example, that 'thoughtless choices ... could have been avoided if we had considered the research and theory of decision-making' (S37). The extract below illustrates transition to an irreversible understanding of EBMgt as a useful concept for management decision-making:

As a result [of my intuitive decision] ... I could not dispense medical supplies, which led to $\mathrm{X}$ being rescued. ... Management is normally viewed as experience-based, thinking on your feet and mainly self-taught instead of using evidence to support your decisions. ... I now know that decisions made just because I think they are right may not be as effective as those made with reference to research evidence. (S38)

The above extract about a regretted decision points to a second mechanism in the T2 transition process, namely a shift from being other-focused to self-focused. The student finds value in the EBMgt approach which she relates personally to herself. A focus on the benefits of EBMgt for the self was similarly evident in the reflections of other students transitioning to an irreversible understanding. When students are involved in a decision they regret and then uncover evidence which shows they could have implemented corrective actions to prevent regret, this experience brings EBMgt into view as 'a useful and practical tool for me' and makes it more difficult to unlearn or forget. As a student explained, 'I experienced first- 
hand how evidence provided by scholarly articles could have significantly improved the decision-making and outcomes achieved by our group' (S39). In this transitional state, the student has learned through personal experience that research does lead to useful information to help oneself prevent regretted decisions:

As the simulation demonstrated, without the correct managerial knowledge, the amateur group [which I belonged to] made several managerial mistakes... These issues led to inefficiency in reaching team goals. However upon researching evidence-based management articles, it was clear that there were some corrective actions that the group could have taken in the simulation by following what was found in these studies with other groups. (S32)

Our data shows the two mechanisms of retrospective reflection on a regretted decision and a self-oriented focus on the benefits of EBMgt help to trigger conceptual progression from an integrative-and-bounded to an irreversible understanding of the threshold concept. Because the student has socially constructed their own 'proof of EBMgt's worth' (S40) grounded in their personal lived experience and feelings of regret about an intuitive decision, unlearning the threshold concept will require considerable effort. Forgetting is also difficult since EBMgt is 'much more prominent within my experience' (S41).

\section{Transition T3: Irreversible to Transformative}

For students who master the threshold concept, exit from the liminal space with a transformative understanding of EBMgt is triggered by a third transition (T3) which brings together and solidifies the integrative, bounded, and irreversible understandings emergent at the $\mathrm{T} 1$ and $\mathrm{T} 2$ transitions. This final transformative understanding is rooted in cumulative experience of the liminal space, so the student sees how EBMgt relates to management theory and practice (integrative), glimpses that EBMgt has contextual boundaries and terminal frontiers in its application to management as a social science (bounded), and is unlikely to forget that in appropriate situations EBMgt has potential value in preventing regretted decisions (irreversible). The extract below illustrates a transformative understanding of EBMgt: 
When I advance to the corporate or managerial world ... I will be interested to see how challenging EBMgt is to implement and whether it improves the quality of decisions being made in a business environment. I will need to ensure I gain access to accurate, timely and suitable data, which could pose a difficulty. However, without experimenting, one will never know (S31).

Two mechanisms appear to be important in this final exit to transformative understanding of EBMgt as a threshold concept: emotional resolution and conceptual settlement. The cumulative experience of engaging with EBMgt resolves the negative emotions associated with liminality and the student reaches a stable understanding of EBMgt as a way of thinking about management that may have practical value in some situations:

'Having had some managerial roles in my working life to date, I certainly would have approached some situations differently after reading the article and researching for the assignment' (S42). Another student signalled conceptual settlement by displaying selfreflexivity about their previous intuitive and rapid decision-making in the military: 'whilst this thought process served me well, it also at times was not the best thought process to employ' (S43). The extract below shows how the mechanisms of emotional resolution and conceptual settlement reinforce each other as students exit the liminal space of threshold concept learning. Through his experience of applying EBMgt, the student no longer feels 'overwhelmed' and recognises EBMgt offers a potential way of thinking about management when future situations eliciting this negative emotion arise:

The skills that I have acquired from this task I hope to apply to my future career. I plan to run a medium-scale business one day, and this assignment has taught me a lot about what to do and what not to do when it comes to turning a group of individuals into a highly functional and successful team. I now know that even if, as a business leader in the future, I ever feel overwhelmed or alone in the decision-making process, there is a wealth of scientific information at my disposal which would increase my chances of success. (S44)

\section{Summary: Student's Conceptual Progression across the Liminal Space}

Our data reveals the transitions that need to occur in student understanding of EBMgt as a threshold concept in order for a student to enter, move through and ultimately exit the 
liminal space. We found that 31 students in our sample (14\%) did not progress beyond the T0 transition and maintained an understanding of EBMgt as troublesome knowledge. Another 84 students in our sample (39\%) understood the integrative-and-bounded nature of EBMgt but did not progress beyond the T1 transition. A further 67 students in our sample (31\%) progressed through the $\mathrm{T} 0, \mathrm{~T} 1$ and $\mathrm{T} 2$ transitions and gained an irreversible understanding of EBMgt as useful for management practice within appropriate contextual boundaries. Finally, 35 students in our sample (16\%) progressed through the T0, T1, T2 and T3 transitions and resolved their cumulative experiences of EBMgt in a way that brought a transformative understanding of EBMgt into view as a disciplinary way of thinking and practising.

To demonstrate how a student might progress conceptually across the liminal space through the T0, T1, T2 and T3 transitions in threshold concept learning, we provide an illustrative case study of one student named Lucy. At the T0 transition, Lucy feels doubt about engaging with EBMgt because the concept does not fit with her preconception of management: 'initially I was quite unsure'. This brings into view the troublesome nature of applying science-based EBMgt to human behaviour in organizations: 'I think I might find implementing EBMgt approaches challenging when working with other people'. During 'the treacherous climb of Mt Everest', Lucy experiences high-activation negative emotions as 'tensions were high ... [and] group members felt vulnerable'. This experience progresses Lucy to the T1 transition as 'the resulting stress of making decisions that were not fully considered' brings the integrated and bounded nature of EBMgt into view. The emotional stimulus is supported by an other-oriented focus in which Lucy glimpses the benefits of EBMgt for generalized others within contextual boundaries. She sees that 'the essence of EBMgt is to increase the effectiveness of workplaces' in decision situations where 'the time frame' allows for evidence search and evaluation. At the T2 transition, Lucy feels 'regrets for not changing their decisions' during a particularly challenging situation in the simulation and 
becomes self-focused as she reflects on how the regretted behaviour within her group could have been prevented: 'if EBMgt had been implemented, decision and organizational structures within my group could have been more closely examined and the culture of the group could have been improved'. Given her personal experience and reflection, Lucy's understanding of EBMgt becomes irreversible to the extent it will be difficult to forget or unlearn: 'I hope to implement my knowledge and experiences gained ... in the years to come'. Finally, at the T3 transition, Lucy's cumulative experiences of the liminal space resolve the negative emotions of liminality and produce conceptual settlement, enabling her to exit the liminal space with a transformed understanding of EBMgt as a way of thinking about management that has practical value in some situations in organizations:

This approach will make it easier for me to identify how to improve rather than continuing within my comfort zone. The EBMgt approach highlights how you are in charge of your own decision, and how you can make changes to your decisions if the opportunity presents itself. When reflecting on daily work practices, this approach will be a useful tool to help me critically reflect upon my decision making and team work skills.

\section{DISCUSSION AND IMPLICATIONS}

\section{The process of threshold concept learning}

In this article, we sought to advance the management learning literature by deepening insight into liminality and threshold concept learning through an empirical study of how undergraduate students engage with the threshold concept of EBMgt. Our particular interest lay in exploring the transitions and mechanisms, including emotions, in the process of navigating the liminal space to a new understanding of EBMgt as a disciplinary way of thinking and practising. We summarise the findings of our empirical study in a process model in Figure 1.

INSERT FIGURE 1 HERE 
As shown in Figure 1, entry into the liminal space is triggered by a confrontation between a learner's existing understanding of management phenomena and their introduction to a new threshold concept as a particular way of thinking and practising in the underlying game of the management discipline. This confrontation elicits doubt and, as the troublesome nature of the threshold concept comes into view, the learner crosses into the liminal space at the T0 transition. The learner is now characterised as liminal, located 'betwixt and between' their old understanding and a new understanding of the threshold concept. The mechanisms of high-activation negative emotions and an other-oriented focus trigger the learner's transition in the liminal space at T1, bringing into view the previously hidden integrative-andbounded characteristics of the threshold concept. At the T2 transition, the irreversible characteristic of the threshold concept is opened up for the learner, activated by the mechanisms of regret and self-oriented focus as the learner reflects on their old understanding and the benefits of engagement with the threshold concept as a way of thinking and practising. For those students who master the threshold concept, the mechanisms of emotional resolution and conceptual settlement trigger exit from the liminal space at the T3 transition. Here, the learner crosses into a transformative understanding of the threshold concept that builds on and solidifies the integrative, bounded, and irreversible understandings that accumulated at the T1 and T2 transitions. Having mastered the threshold concept - and in contrast to learners 'stuck' at transitions in the liminal space the post-liminal learner understands the threshold concept is one possible way of thinking among the multiple ways of thinking and practising nested within the boundaries of a disciplinary game.

\section{Contributions to debates on threshold concepts, liminality and management practice}

Our process model makes three substantive contributions. First, we provide rich insight into the processes through which threshold concepts act as a 'catalyst for learning' 
(Yip \& Raelin, 2012:348). In contrast to aggregated and relatively static views of threshold concept characteristics that have tended to dominate the literature on threshold learning (Hibbert \& Cunliffe, 2015; Meyer \& Land, 2005), our findings reveal that particular characteristics of threshold concepts may come into view for learners at different transitions in a cumulative process into, through and (potentially) out of the liminal space. Our process model indicates that grasping the transformative potential of a threshold concept involves key transition points from an initial struggle with troublesome knowledge to glimpsing the integrated and bounded nature of the threshold concept through an experience that is difficult to unlearn. These findings provide a new lens for understanding the 'stickiness' of threshold concepts (Davies \& Mangan, 2007; Meyer \& Land, 2006) by suggesting that learners can become stuck in the liminal space when they maintain a focus on an 'other' rather than the self. Learners who fail to transition from T1 to T2 avoid moving towards an irreversible understanding by keeping their focus on how a hypothetical 'other' might engage with the threshold concept. The absence of self-focused reflection on the learner's experience with the threshold concept makes it easier to unlearn.

Second, we extend the literature on liminality in learning processes by opening up how transitions through liminal spaces play out as an interrelated cognitive and affective process. By focusing on learning processes, we capture the temporal nature of liminality that is missing from much of the literature (Bamber et al., 2017; Söderlund \& Borg, 2017). Our process model elaborates the transition points and mechanisms related to doubt, highactivation negative emotions, regret, and emotional resolution that trigger entry into, progression through or getting stuck within, and exit from a liminal space when a learner engages with and masters a threshold concept. While prior studies have highlighted doubt as the key emotion felt by liminal learners (Hawkins \& Edwards, 2015; Hay \& SamraFredericks, 2016), our findings indicate other types of emotions such as worry, panic, 
surprise, and regret and their strength of activation are salient in the process of transitioning through a liminal space. Rather than liminality simply triggering negative emotions, as is implied by some researchers (Beard et al., 2007; Gilmore \& Anderson, 2011; Kempster et al., 2015), our findings support framing emotions as mechanisms that facilitate access to a liminal space (Hay \& Samra-Fredericks, 2016).

Third, we advance wider debates about disciplinary ways of thinking and practising in management and critiques of the place of EBMgt within the discipline's underlying game (Morrell, 2008; Morrell \& Learmonth, 2015; Tourish, 2013). Specifically, we show how educators can help undergraduate students engage critically with threshold concepts like EBMgt as one particular way of thinking and practising amongst the multiple ways that comprise management as a pluralistic and inclusive academic discipline. We speculate that as the novice student's knowledge of the discipline advances through engagement with other threshold concepts in their program of study, the initial threshold understanding of EBMgt as one possible way of thinking about management will be refined, extended, nuanced, and critiqued but not forgotten. An implication of our empirical study is that when management educators approach teaching and learning at the undergraduate level as nests of inter-related and bounded threshold concepts and conceptions (Yip \& Raelin, 2012; Hawkins \& Edwards, 2015), a learner's existing understandings can be refined and critiqued as they engage with more threshold concepts by navigating liminal spaces throughout a program of study. Having opened up the liminal processes in undergraduate student learning of EBMgt as a threshold concept, we invite future research to explore the processes of transitioning through the liminal space for learners of different types of threshold concepts and threshold conceptions in a wide range of courses at the undergraduate, postgraduate, and MBA levels. No single coherent vision of the management discipline exists and the approach that EBMgt encapsulates is but one of many possible bases for practice that can exist in sympathy or 
tension with others, echoing the sentiments of Hawkins and Edwards (2015) in relation to the field of leadership.

\section{Further research}

We encourage future research that explores students' experiences of liminality with alternative threshold concepts and more encompassing threshold conceptions in the underlying 'game' of management as a discipline. We suggest that such research may also be conducted in different ways - such as through close observation in informal learning contexts - to explore alternative possible dynamic relationships between threshold concepts and liminality. While our data have shown how engagement with a particular threshold concept can lead individuals into the experience of liminality, we speculate that the destabilizing experience of liminality - however it is attained - may open up individuals to explore their understandings in a different way. This could include 'reaching out' for different concepts that can help them to navigate a way through the liminal space. Going further, there is also merit in exploring Hibbert and Cunliffe's (2015) suggestion that for some concepts, threshold concept learning may lead a learner to a different understanding of oneself. This could prompt re-entry into liminal spaces and thus lead to more complex cycles of doubt and learning. In conclusion, we strongly encourage others to continue to add to explorations in this area, through different modes of research which may reveal alternative and more complex dynamics. 


\section{REFERENCES}

Bamber, M., Allen-Collinson, J., \& McCormack, J. 2017. Occupational limbo, transitional liminality and permanent liminality: New conceptual distinctions. Human Relations, 70(12): 15141537.

Barends, E., \& Briner, R. B. 2014. Teaching evidence-based practice: Lessons from the pioneers. An interview with Amanda Burls and Gordon Guyatt. Academy of Management Learning and Education, 13(3): 476-483.

Beard, C., Clegg, S., \& Smith, K. 2007. Acknowledging the affective in higher education. British Educational Research Journal, 33(2): 235-252.

Bolinger, A. R., \& Brown, K. D. 2015. Entrepreneurial failure as a threshold concept: The effects of student experiences. Journal of Management Education, 39(4): 452-475.

Borg, E., \& Soderland, J. 2015. Liminality competence: An interpretative study of mobile project workers' conception of liminality at work. Management Learning, 46(3): 260-279.

Briner, R. B., Denyer, D., \& Rousseau, D. M. 2009. Evidence-based management: Concept cleanup time? Academy of Management Perspectives, 23(4): 19-32.

Burch, G. F., Burch, J. J., Bradley, T. P., \& Heller, N. A. 2015. Identifying and overcoming threshold concepts and conceptions: Introducing a conception-focused curriculum to course design. Journal of Management Education, 39(4): 476-496.

Corbin, J., \& Strauss, A. 2008. Basics of Qualitative Research (Third ed.). Thousand Oaks, CA: Sage.

Cousins, G. 2006. Threshold concepts, troublesome knowledge and emotional capital: An exploration into learning about others. In J. H. F. Meyer, \& R. Land (Eds.), Overcoming Barriers to Student Understanding: Threshold Concepts and Troublesome Knowledge. London: Routledge.

Davies, P., \& Mangan, J. 2007. Threshold concepts and the integration of understanding in economics. Studies in Higher Education, 32(6): 711-726.

Duarte, F. 2013. Sustainability learning threshold in an MBA subject: An exploratory study. Journal of International Business Education, 8: 119-142.

Dyer, S. L., \& Hurd, F. 2016. "What's going on?" Developing reflexivity in the management classroom: Fron surface to deep learning and everything in between. Academy of Management Learning \& Education, 15(2): 287-303.

Gilmore, S., \& Anderson, V. 2011. Anxiety and experience-based learning in a professional standards context. Management Learning, 43(1): 75-95.

Gilmore, S., \& Anderson, V. 2016. The emotional turn in higher education: A psychoanalytic contribution. Teaching in Higher Education 21(6): 686-699.

Gourlay, L. 2009. Threshold practices: Becoming a student through academic literacies. London Review of Education, 7(2): 181-192.

Hawkins, B., \& Edwards, G. 2015. Managing the monsters of doubt: Liminality, threshold concepts and leadership learning. Management Learning, 46(1): 24-43.

Hay, A., \& Samra-Fredericks, D. 2016. Desperately seeking fixedness: Practitioners' accounts of 'becoming doctoral researchers'. Management Learning, 47(4): 407-423.

Hibbert, P., \& Cunliffe, A. L. 2015. Responsible management: Engaging moral reflexive practice through threshold concepts. Journal of Business Ethics, 127(1): 177-188.

Hornung, S. 2012. Beyond "New Scientific Management": Critical reflections on the epistemology of evidence-based management. In D. Rousseau (Ed.), The Oxford Handbook of EvidenceBased Management: 389-403. Oxford: Oxford University Press.

Irvine, N., \& Carmichael, P. 2009. Threshold concepts: A point of focus for practitioner research. Active Learning in Higher Education, 10(2): 103-119.

Kempster, S., Turner, A., Heneberry, P., Stead, V., \& Elliott, C. 2015. The "Finger Puppets": Examining the use of artifacts to create liminal moments in Management Education. Journal of

Management Education, 39(3): 433-438. 
Kepes, S., Bennett, A. A., \& McDaniel, M. A. 2014. Evidence-based management and the trustworthiness of our cumulative scientific knowledge: Implications for teaching, research, and practice. Academy of Management Learning and Education, 13(3): 446-466.

Learmonth, M. 2006. Dialogue: "Is there such a thing as evidence-based management?": A commentary on Rousseau's 2005 presidential address. Academy of Management Review, 31: 1089-1093.

Learmonth, M. 2008. Evidence-based management: A backlash against pluralism in organizational studies. Organization, 15: 283-291.

Lucas, U., \& Mladenovic, R. 2007. The potential of threshold concepts: an emerging framework for educational research and practice. London Review of Education, 5(3): 237-248.

Meyer, J. H. F., \& Land, R. 2003. Threshold concepts and troublesome knowledge: Linkages to ways of thinking and practising within the disciplines, ETL Project: Occasional Report 4. Edinburgh.

Meyer, J. H. F., \& Land, R. 2005. Threshold concepts and troublesome knowledge (2): Epistemological considerations and a conceptual framework for teaching and learning. Higher Education, 49: 255-289.

Meyer, J. H. F., \& Land, R. L. 2006. Overcoming barriers to student understanding: Threshold concepts and troublesome knowledge. London: Routledge.

Morrell, K. 2008. The narrative of 'evidence-based management: A polemic. Journal of Management Studies, 45(3): 613-635.

Morrell, K. 2012. Evidence-based dialectics. Organization, 9: 461-479.

Morrell, K., \& Learmonth, M. 2015. Against evidence-based management, for management learning. Academy of Management Learning and Education, 14(4): 520-533.

Morrell, K., Learmonth, M., \& Heracleous, L. 2015. An archaeological critique of 'evidence-based management': One digression after another. British Journal of Management, 26(3): 529543.

Nichols, E., \& Wright, A. L. 2015. Using the Everest team simulation to teach threshold concepts. Journal of Management Education, 39(4).

Perkins, D. 1999. The many faces of constructivism. Educational Leadership, 57(3): 6-11.

Perkins, D. 2006. Constructivism and troublesome knowledge. In J. H. F. Meyer, \& R. Land (Eds.), Overcoming barriers to student understanding: threshold concepts and troublesome knowledge: 33-47. London: Routledge.

Pfeffer, J., \& Sutton, R. I. 2006. Hard Facts, Dangerous Half-Truths, and Total Nonsense: Profiting from Evidence-based Management. Boston: Harvard Business Review.

Reay, T., Berta, W., \& Kohn, M. K. 2009. What's the evidence on evidence-based management? Academy of Management Perspectives, 23(4): 5-18.

Romme, A. G. L., \& Seggelen-Damen, I. C. M. 2015. Taking nothing for granted in management education: a systemic perspective on the role of reflective questioning. Organization Management Journal, 12(2): 76-86.

Rousseau, D. M. 2006. Is there such a thing as 'evidence-based management'? Academy of Management Review, 31(2): 256-269.

Rousseau, D. M., \& McCarthy, S. 2007. Educating managers from an evidence-based perspective. Academy of Management Learning and Education, 6(1): 84-101.

Rynes, S. L., Rousseau, D. M., \& Barends, E. 2014. Change the world: Teach evidence-based practice! Academy of Management Learning and Education, 13(3): 305-321.

Scheja, M., \& Pettersson, K. 2009. Transformation and contextualization: Conceptualizing students' conceptual understandings of threshold concepts in calculus. Higher Education., 59(2): 221241.

Simpson, R., Sturges, J., \& Weight, P. 2009. Transient, unsettling and creative space: Experiences of liminality through the accounts of Chinese students in a UK-based MBA. Management Learning, 41(1): 53-70. 
Söderlund, J., \& Borg, E. 2017. Liminality in management and organization studies: Process, position and place. International Journal of Management Reviews, 0(0): 1-23 https://doi.org/10.1111/ijmr.12168.

Strauss, A., \& Corbin, J. 1990. Basics of Qualitative Research: Grounded Theory Procedures and Techniques. Newbury Park, CA: Sage.

Tempest, S., \& Starkey, K. 2004. The efefcts of liminality on individual and organizational learning. Organization Studies, 25(4): 507-527.

Tourish, D. 2013. "Evidence-based management" or "evidence-oriented organizing"? A critical realist perspective. Organization, 20(2): 173-192.

Trank, C. Q. 2014. "Reading" evidence-based management: The possibilities of interpretation. Academy of Management Learning and Education, 13(3): 381-395.

Turner, V. 1977. The Ritual Process. Ithaca, NY: Cornell University Press.

Van Gennep, A. 1960. The Rites of Passage (M. B. Vizedom, \& G. L. Caffee, Trans.). London: Routledge and Kegan Paul.

Vidal, N., Smith, R., \& Spetic, W. 2015. Designing and teaching Business \& Society courses from a threshold concept approach. Journal of Management Education, 39(4): 497-530.

Wright, A. L., \& Gilmore, A. 2012. Threshold concepts and conceptions: Student learning in introductory management courses. Journal of Management Education, 36(5): 614-635.

Wright, A. L., \& Hibbert, P. 2015. Threshold concepts in theory and practice. Journal of Management Education, 39(4): 443-451.

Wright, A., Irving, G., Hibbert, P. \& Greenfield, G. 2018. Student understandings of evidence-based management: Ways of doing and being. Academy of Management Learning and Education, online early doi:10.5465/amle.2016.0249.

Yip, J., \& Raelin, J. 2012. Threshold concepts and modalities for teaching leadership practice. Management Learning, 43(3): 333-354. 
FIGURE 1: PROCESS OF MOVING THROUGH THE LIMINAL SPACE IN THRESHOLD CONCEPT LEARNING

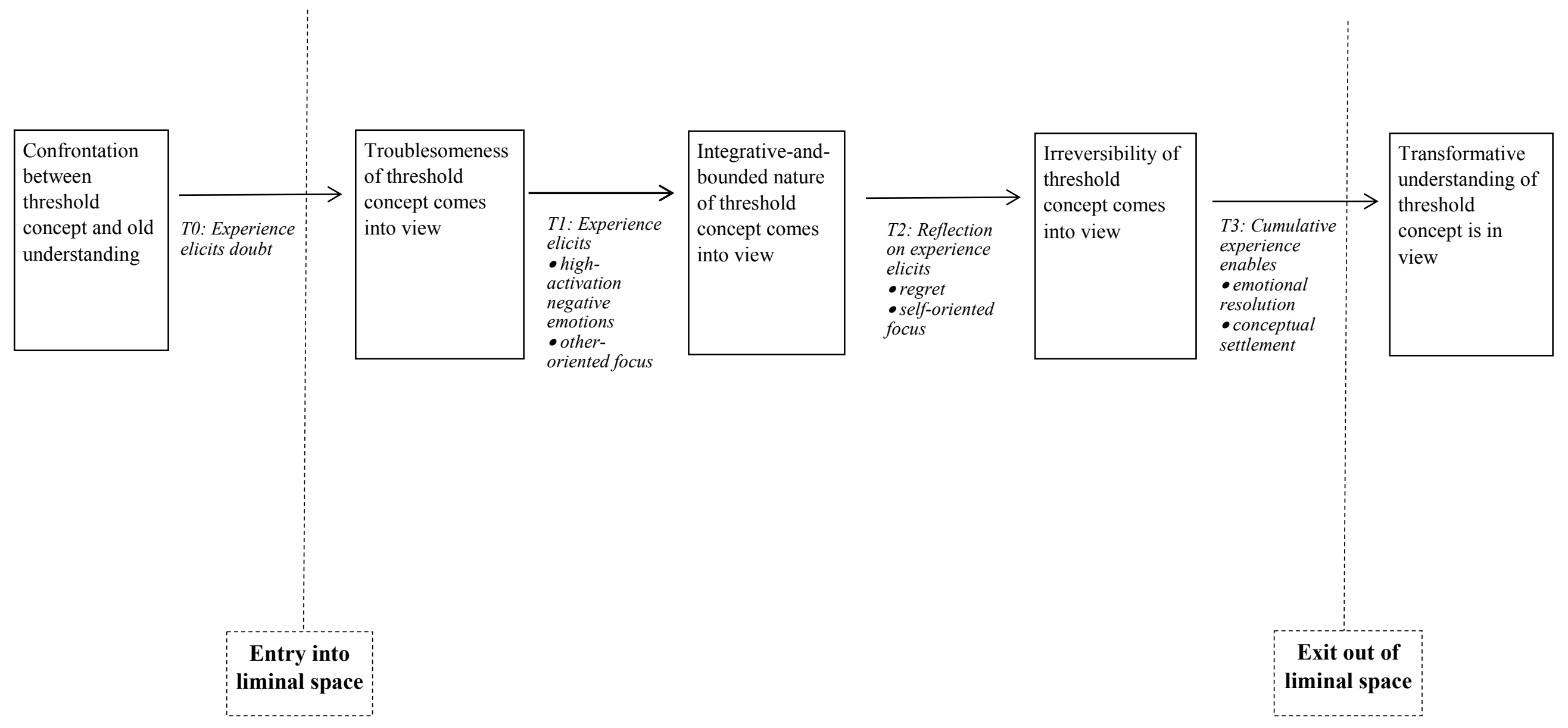

